\title{
UROPEPSIN EXCRETION BY MAN. III. UROPEPSIN EXCRETION BY PATIENTS WITH PEPTIC ULCER AND OTHER LESIONS OF THE STOMACH ${ }^{1,2}$
}

\author{
By CLARENCE J. PODORE, ROBERT H. BROH-KAHN, AND I. ARTHUR MIRSKY \\ (From The May Institute for Medical Research, The Jererish Hospital, and the Departments of \\ Medicine and Psychiatry, University of Cincinnati College of Medicine, Cincinnati)
}

(Received for publication August 16, 1948)

In preceding papers $(1,2)$ we have outlined results which indicate that uropepsin excretion may serve as a useful index of the rate of the "intrinsic" or endocrine-like activity of the pepsinogen-secreting cells of the gastric mucosa. Data were also presented concerning the uropepsin excretion patterns of healthy, adult male subjects. Since various lesions of the stomach and duodenum are associated with either an increase or a decrease in the rate of gastric activity, the uropepsin excretions of patients suffering from a variety of conditions affecting the gastrointestinal tract were investigated.

\section{METHODS}

The urine was collected and assayed according to the procedure described in a previous communication (1). The unit of uropepsin used is the same as defined earlier, namely, that amount of uropepsin which, in the standard ten-minute assay, liberates $1 \mathrm{mg}$. of "tyrosine-like" acid soluble material.

The patients utilized in the study included only those whose diagnosis had been established by means of objective criteria universally accepted as adequate for this purpose. Inasmuch as the opportunity has not yet been presented to study a sufficiently large number of healthy women and since our previous study of healthy subjects was confined to men, this report will be limited except where otherwise noted, to the presentation of results obtained from male patients only.

\section{RESULTS}

In the preceding paper (2), some of the factors that define and characterize the uropepsin excretion of healthy men were discussed. The influence of these factors was revealed by the application of statistical procedures to the assembled data. The

1 Presented in part before the American Physiological Society, Atlantic City, March, 1948.

2 Aided in part by a grant from the Mental Hygiene Council, Research Grants Division of the U. S. Public Health Service. data reported herein were subjected to the same types of analysis as have been utilized in the preceding paper. The results of these statistical analyses revealed the fact that certain of the conclusions obtained from the study of uropepsin excretion of healthy men can be extended to the results obtained from the patients considered in this paper. Thus, as with the group of normal men, so with the present group of patients it was possible to demonstrate that $(a)$ data concerning uropepsin excretions should be expressed as log units per hour rather than in terms of the arithmetic values; (b) data concerning the logs of the units of uropepsin excretions of any one patient, from day to day, group themselves around a mean value in the form of a normal distribution curve; $(c)$ uropepsin excretion is not markedly affected by wide fluctuations in the rate of urine formation; $(d)$ diurnal fluctuations in uropepsin excretion fall well within the limits of the fluctuations observed from day to day and, accordingly, uropepsin excretion remains relatively constant throughout the day.

In consideration of these facts, uropepsin excretions will be expressed only in terms of the log units per hour. In view of the lack of an essential difference between uropepsin excretion in urine formed during the waking hours and during sleeping hours of the same day, and in view of the marked advantages inherent in the collection and analysis of specimens formed only during the hours of sleep (2), we shall present data obtained solely from the analysis of "night urines." However, it should be noted that similar results were obtained from the collection of "day urines," in those patients in whom the collection of such samples was found to be a practical procedure.

\section{A. Peptic ulcer}

Uropepsin assays were performed on 695 "night" specimens of urine obtained from 30 pa- 
tients with benign gastric or duodenal ulcers. In every one of these subjects the diagnosis had been established as the result of unequivocal roentgenologic, gastroscopic or post-operative histopathologic examination of the lesion. The results of all of the uropepsin determinations performed on night specimens of urine obtained from these 30 male patients for from one to 207 consecutive nights are summarized in Table $I$ and reveal that the mean excretion is approximately twice that observed in healthy men (2).

As was found to be the case with normal subjects, no sampling error has been introduced as far as the entire group of ulcer patients is concerned. The mean value for the uropepsin excretion per hour for the entire group was not found to be radically changed if only the first assay, the mean of the first four assays, or the mean of all of the available assays for each subject is used for the calculation of the mean uropepsin ex-

TABLE I

Uropepsin excretion of male patients with peptic ulcer

\begin{tabular}{|c|c|c|c|c|c|c|c|}
\hline \multirow{2}{*}{ Subject } & \multicolumn{5}{|c|}{ First four assays } & \multicolumn{2}{|c|}{ All assays } \\
\hline & 1 & 2 & 3 & 4 & Mean & Number & Mean \\
\hline $\begin{array}{l}\text { P. C. } \\
\text { H. C. } \\
\text { T. C. } \\
\text { Da. } \\
\text { J. D. } \\
\text { D. E. } \\
\text { S. F. } \\
\text { V. G. } \\
\text { H. G. } \\
\text { G. K. } \\
\text { H. K. } \\
\text { W. M. } \\
\text { L. M. } \\
\text { J. R. } \\
\text { J. S. } \\
\text { J. W. } \\
\text { Zi. } \\
\text { Ne. } \\
\text { M. G. }\end{array}$ & $\begin{array}{r}.76 \\
.38 \\
.53 \\
1.06 \\
.60 \\
.72 \\
.49 \\
.26 \\
.28 \\
.28 \\
1.05 \\
.81 \\
.90 \\
1.14 \\
.87 \\
.83 \\
.40 \\
1.43 \\
.91 \\
.57 \\
1.06 \\
.53 \\
1.02 \\
.76 \\
1.17 \\
.46 \\
.58 \\
1.32 \\
.76 \\
.30\end{array}$ & $\begin{array}{r}1.03 \\
.70 \\
.56 \\
1.03 \\
.60 \\
.68 \\
.91 \\
.88 \\
.30 \\
.67 \\
1.55 \\
.61 \\
.98 \\
.30 \\
.74 \\
.59 \\
.93 \\
.75 \\
.95 \\
.79 \\
.86 \\
.58 \\
\\
.45 \\
.68 \\
.45 \\
.20\end{array}$ & $\begin{array}{c}.40 \\
.62 \\
.63 \\
1.03 \\
.52 \\
.96 \\
.56 \\
.81 \\
.11 \\
1.07 \\
.76 \\
\overline{1} \\
1.05 \\
.99 \\
.56 \\
.58 \\
.95 \\
.56 \\
.76 \\
.88 \\
.90 \\
.82 \\
.86 \\
.95\end{array}$ & $\begin{array}{r}1.03 \\
.88 \\
.69 \\
1.03 \\
.51 \\
.76 \\
.80 \\
.56 \\
.92 \\
1.28 \\
1.31 \\
- \\
.99 \\
.83 \\
.54 \\
.60 \\
1.06 \\
- \\
.57 \\
.89 \\
- \\
.32 \\
.75 \\
1.24 \\
.93\end{array}$ & $\begin{array}{r}.81 \\
.65 \\
.60 \\
1.04 \\
.56 \\
.78 \\
.69 \\
.63 \\
.40 \\
.83 \\
1.17 \\
.71 \\
.90 \\
1.04 \\
.59 \\
.85 \\
.52 \\
.89 \\
.92 \\
.69 \\
.93 \\
.68 \\
.84 \\
.76 \\
1.17 \\
.53 \\
.71 \\
.90 \\
.76 \\
.60\end{array}$ & $\begin{array}{r}8 \\
207 \\
46 \\
64 \\
13 \\
14 \\
13 \\
42 \\
16 \\
9 \\
4 \\
2 \\
1 \\
7 \\
2 \\
5 \\
5 \\
6 \\
10 \\
3 \\
2 \\
12 \\
16 \\
1 \\
1 \\
6 \\
29 \\
4 \\
1 \\
10\end{array}$ & $\begin{array}{r}.96 \\
.63 \\
.66 \\
.96 \\
.54 \\
.88 \\
.65 \\
.68 \\
.62 \\
.70 \\
1.17 \\
.71 \\
.90 \\
.99 \\
.30 \\
.82 \\
.56 \\
.78 \\
.88 \\
.69 \\
.93 \\
.49 \\
.96 \\
.76 \\
1.17 \\
.58 \\
.67 \\
.90 \\
.76 \\
.63\end{array}$ \\
\hline $\begin{array}{l}\text { Mean } \\
\text { excretion }\end{array}$ & .74 & .72 & .75 & .84 & .76 & & .76 \\
\hline
\end{tabular}

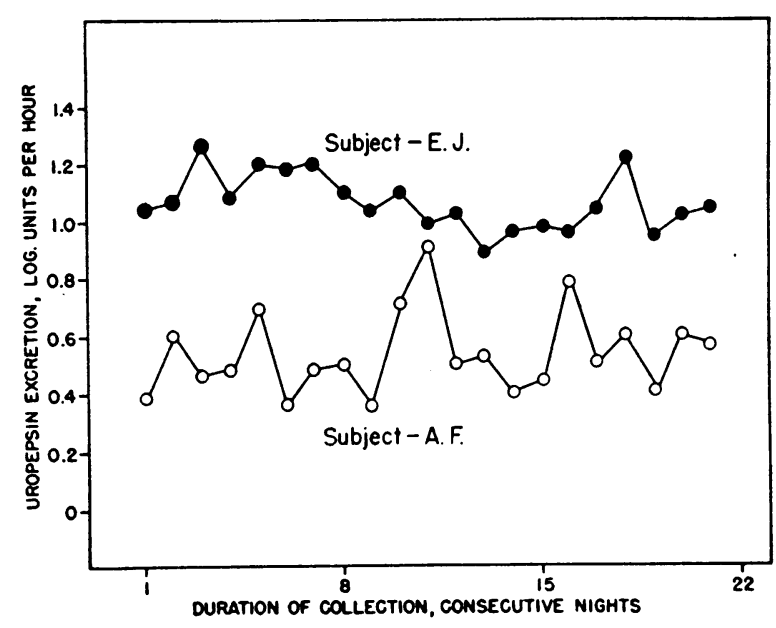

Fig. 1. Uropepsin Excretion Patterns of Two Ulcer Patients

Each point represents a value obtained from analysis of a "night" specimen of urine. The illustrated results were obtained from such urines collected for 21 consecutive nights.

cretion for the entire group. It is apparent, therefore, that a single sample taken from each of a group of men may be used to determine whether a group of such individuals excrete uropepsin at a rate similar to that characteristic of the group of male patients with peptic ulcers.

In order to derive a quantitative estimate of the significance of the observed fluctuations in uropepsin excretions within and among subjects, an analysis of variance (3) was performed on the data summarized in Table I. For this purpose, variances were calculated on the basis of the first four assays of all ulcer patients with four or more assays and on the basis of the first ten assays of all patients with ten or more assays. The results of these calculations are presented in Table II. For the sake of comparison of groups, similar calculalations on data from healthy males, taken from Table IV of the preceding paper (2), have been included.

As was anticipated, the results of both sets of calculations essentially confirmed one another; the significance of certain differences became more apparent in the analysis using the greater number (ten) of samples. It is obvious that the variance within men with ulcer was much less than the variance among men with ulcer and the chances are less than one in a hundred and one in a thousand that this could be due to random sampling. Such 
TABLE II

Analysis of variance in uropepsin excretion of men with peptic ulcers

The variance was calculated from data obtained from the first four and first ten consecutive assays of specimens from all subjects with the corresponding or greater number of assays. The statistics for the healthy men were taken from Table IV of the preceding paper (2). "All men" refers to the sum of ulcer patients plus healthy men.

\begin{tabular}{|c|c|c|c|c|c|c|c|c|c|c|}
\hline \multirow{2}{*}{$\begin{array}{l}\text { Source of } \\
\text { variation }\end{array}$} & \multicolumn{2}{|c|}{ Sum of squares } & \multicolumn{2}{|c|}{ Degrees of freedom } & \multicolumn{3}{|c|}{ Variance } & \multicolumn{3}{|c|}{$\mathbf{F}$} \\
\hline & $\begin{array}{c}\text { Four } \\
\text { samples }\end{array}$ & $\begin{array}{c}\text { Ten } \\
\text { samples }\end{array}$ & $\begin{array}{c}\text { Four } \\
\text { samples }\end{array}$ & $\begin{array}{c}\text { Ten } \\
\text { samples }\end{array}$ & & $\begin{array}{c}\text { Four } \\
\text { samples }\end{array}$ & $\begin{array}{c}\text { Ten } \\
\text { samples }\end{array}$ & & $\begin{array}{c}\text { Four } \\
\text { samples }\end{array}$ & $\begin{array}{c}\text { Ten } \\
\text { samples }\end{array}$ \\
\hline Among all men & 8.8605 & 10.4891 & 43 & 27 & A & 0.2061 & 0.3885 & \multirow{2}{*}{$\mathrm{A} / \mathrm{B}$} & \multirow{2}{*}{$3.77 \ddagger$} & \multirow{2}{*}{$8.65 \ddagger$} \\
\hline Within all men & 7.2127 & 11.3219 & 132 & 252 & B & 0.0546 & 0.0449 & & & \\
\hline Among samples & 0.1211 & 0.2620 & 3 & 9 & $\mathrm{C}$ & 0.0404 & 0.0291 & \multirow{2}{*}{$C / D$} & \multirow{2}{*}{0.73} & \multirow{2}{*}{0.64} \\
\hline Interaction & 7.0916 & 11.0599 & 129 & 243 & D & 0.0550 & 0.0453 & & & \\
\hline $\begin{array}{l}\text { Ulcer patients- } \\
\text { healthy men }\end{array}$ & 3.7127 & 4.2697 & 1 & 1 & $\mathbf{E}$ & 3.7127 & 4.2697 & $\mathrm{E} / \mathrm{B}$ & $68.00 \ddagger$ & $95.09 \ddagger$ \\
\hline $\begin{array}{c}\text { Among ulcer } \\
\text { patients }\end{array}$ & 3.1971 & 2.8239 & 21 & 12 & $\mathbf{F}$ & 0.1522 & 0.2353 & \multirow{2}{*}{$F / G$} & \multirow{2}{*}{$2.46 \dagger$} & \multirow{2}{*}{4.75} \\
\hline $\begin{array}{l}\text { Within ulcer } \\
\text { patients }\end{array}$ & 4.0869 & 5.7901 & 66 & 117 & G & 0.0619 & 0.0495 & & & \\
\hline Among samples & 0.2442 & 0.3744 & 3 & 9 & $\mathbf{H}$ & 0.0814 & 0.0416 & \multirow{2}{*}{$\mathrm{H} / \mathrm{I}$} & \multirow{2}{*}{1.33} & \multirow{2}{*}{0.83} \\
\hline Interaction & 3.8427 & 5.4157 & 63 & 108 & $\mathbf{I}$ & 0.0610 & 0.0501 & & & \\
\hline $\begin{array}{l}\text { Among healthy } \\
\text { men }\end{array}$ & 1.9506 & 3.3955 & 21 & 14 & $\mathbf{J}$ & 0.0929 & 0.2425 & \multirow{2}{*}{$\mathrm{J} / \mathrm{K}$} & \multirow{2}{*}{$1.96^{*}$} & \multirow{2}{*}{$5.91 t$} \\
\hline $\begin{array}{l}\text { Within healthy } \\
\text { men }\end{array}$ & 3.1259 & 5.5317 & 66 & 135 & $\mathbf{K}$ & 0.0474 & 0.0410 & & & \\
\hline Among samples & 0.0033 & 0.0212 & 3 & 9 & $\mathbf{L}$ & 0.0011 & 0.0024 & \multirow{2}{*}{$\mathrm{L} / \mathrm{M}$} & \multirow{2}{*}{0.02} & \multirow{2}{*}{0.05} \\
\hline Interaction & 3.1226 & 5.5529 & 63 & 126 & $\mathbf{M}$ & 0.0496 & 0.0441 & & & \\
\hline Total & 16.0732 & 21.8110 & 175 & 279 & & 0.0918 & 0.0782 & & & \\
\hline
\end{tabular}

* Significant at $5 \%$ level. † Significant at $1 \%$ level. $\ddagger$ Significant at $0.1 \%$ level.

findings indicate that each ulcer patient excreted uropepsin at a fairly characteristic rate subject, of course, to minor fluctuations from day to day. The differences among excretion rates of peptic ulcer patients are illustrated graphically in Figure 1 which compares the uropepsin excretion rates per hour of two particular patients during consecutive nights.

The distribution of the mean uropepsin excretion rates of the ulcer patients is graphed in Figure 2 , in which the cumulative frequency of men expressed on a probability scale is plotted against units excreted per hour on a logarithmic scale. Since there is no systematic deviation from a rectilinear relation, the plot indicates that the mean values of all of the excretion results are arranged in the form of a normal distribution curve. Included in Figure 2 is a similar plot of the data ob- tained from the study of healthy men (2) which reveals that the ulcer group excretes approximately twice as much uropepsin as does the healthy group.

\section{B. Pernicious anemia}

It has already been demonstrated by Farnsworth et al. (4) that patients with pernicious anemia excrete no uropepsin. In our own studies we have also had the opportunity to perform uropepsin assays on specimens of urine obtained from patients with pernicious anemia. A total of 72 assays was performed on samples of urine collected for from one to 20 consecutive nights from nine patients with pernicious anemia. In every case, no uropepsin was detected. Thus, our own results confirm those of Farnsworth et al. (4) in regard to the absence of uropepsin in the urine of such patients. 
TABLE III

Uropepsin excretion by patients with gastric complaints without ulcer

\begin{tabular}{|c|c|c|c|c|c|c|c|c|}
\hline \multirow{2}{*}{ Patient } & \multirow{2}{*}{ Diagnosis } & \multicolumn{5}{|c|}{ First four assays } & \multicolumn{2}{|c|}{ All assays } \\
\hline & & 1 & 2 & 3 & 4 & Mean & Num- & Mean \\
\hline $\begin{array}{l}\text { M. S. } \\
\text { W. G. } \\
\text { W. B. } \\
\text { J. C. } \\
\text { C. B. } \\
\text { H. C. } \\
\text { W. K. }\end{array}$ & $\begin{array}{l}\text { Gastric Ca } \\
\text { Functional } \\
\text { Gastric Ca } \\
\text { Gastric Ca } \\
\text { Chronic gastritis } \\
\text { Spastic duodenitis } \\
\text { Chronic chole- } \\
\text { cystitis }\end{array}$ & $\begin{array}{r}.38 \\
.48 \\
.54 \\
0 \\
.58 \\
.18 \\
0\end{array}$ & $\begin{array}{r}.52 \\
.23 \\
.52 \\
0 \\
.20 \\
.26 \\
0\end{array}$ & $\begin{array}{r}.18 \\
.71 \\
.04 \\
.62 \\
.78 \\
0 \\
0\end{array}$ & $\begin{array}{r}.60 \\
.51 \\
.51 \\
.56 \\
.62 \\
0\end{array}$ & $\begin{array}{l}.42 \\
.48 \\
.40 \\
.21 \\
.53 \\
.27 \\
0\end{array}$ & $\begin{array}{r}10 \\
40 \\
11 \\
3 \\
31 \\
7 \\
4\end{array}$ & $\begin{array}{l}.49 \\
.75 \\
.21 \\
.21 \\
.44 \\
.20 \\
0\end{array}$ \\
\hline $\begin{array}{l}\text { K. } \\
\text { S. McQ. } \\
\text { S. }\end{array}$ & $\begin{array}{l}\text { Gastric prolapse } \\
\text { Gastric Ca } \\
\text { Epigastric pain } \\
\text { etiology un- } \\
\text { known }\end{array}$ & $\begin{array}{l}.72 \\
.15 \\
.92\end{array}$ & $\begin{array}{l}.43 \\
.08 \\
.28\end{array}$ & $\begin{array}{l}.57 \\
.30 \\
.61\end{array}$ & $\begin{array}{l}.15 \\
.81 \\
.90\end{array}$ & $\begin{array}{l}.47 \\
.34 \\
.68\end{array}$ & $\begin{array}{r}7 \\
11 \\
10\end{array}$ & $\begin{array}{l}.45 \\
.39 \\
.52\end{array}$ \\
\hline$\stackrel{\text { T. }}{\mathrm{G} .} \mathbf{W}$. & $\begin{array}{l}\text { Gastric Ca } \\
\text { Hematemesis } \\
\text { etiology un- } \\
\text { known }\end{array}$ & $\begin{array}{l}.68 \\
.66\end{array}$ & $\begin{array}{l}.69 \\
.53\end{array}$ & $\begin{array}{l}\mathbf{0} \\
\mathbf{0}\end{array}$ & $\begin{array}{l}.56 \\
.52\end{array}$ & $\begin{array}{l}.48 \\
.43\end{array}$ & $\begin{array}{l}6 \\
5\end{array}$ & $\begin{array}{l}.60 \\
.38\end{array}$ \\
\hline $\begin{array}{l}\text { G. F. } \\
\text { E. S. }\end{array}$ & $\begin{array}{l}\text { Ulcer scar } \\
\text { Gastric prolapse }\end{array}$ & $\begin{array}{r}.84 \\
1.04\end{array}$ & $\begin{array}{l}.64 \\
.70 \\
\end{array}$ & $\begin{array}{r}.88 \\
1.00\end{array}$ & $\begin{array}{r}.73 \\
1.18 \\
\end{array}$ & $\begin{array}{l}.77 \\
.98\end{array}$ & $\begin{array}{l}60 \\
42\end{array}$ & $\begin{array}{l}.77 \\
.66\end{array}$ \\
\hline \multicolumn{2}{|c|}{ Mean excretion } & .51 & .36 & .41 & .59 & .46 & & .43 \\
\hline
\end{tabular}

\section{Gastric complaints, with no demonstrable peptic ulcer}

Urine was obtained from a number of patients complaining of ulcer-like and various other complaints referable to the gastrointestinal tract. Such patients included only those in whom no roent- genologic, gastroscopic or histopathologic evidence of peptic ulcer could be obtained. Included in this group are patients whose clinical symptomology was suggestive of peptic ulcer, patients with carcinomatous lesions of the stomach, and patients with ill-defined gastric complaints.

Uropepsin assays were performed on a total of 247 specimens of urine obtained from 14 such subjects. The results are presented in Table III which demonstrates that most of these patients excreted uropepsin at rates similar to those observed in the group of healthy men. That is, they excreted uropepsin at rates appreciably lower than those characteristic of the uropepsin excretion of patients with proven peptic ulcer.

\section{DISCUSSION}

The differences noted in the uropepsin excretion of patients with peptic ulcer as contrasted with that of healthy men and those with other types of diseases, are of great interest. The analysis of variance presented in Table II indicates that a significant difference exists between the ulcer group and the healthy group of subjects. The probability is far less than one in a thousand that the

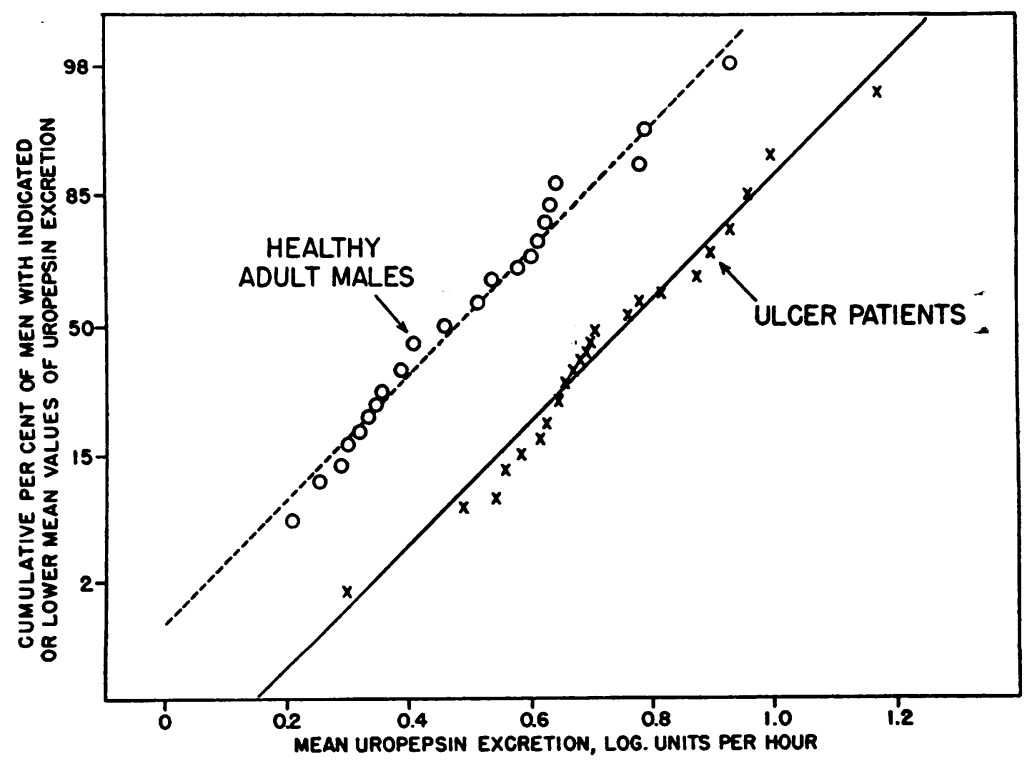

Fig. 2. Frequency Distributions of Mean URopepsin Excretions of Healthy Men and Patients with Peptic Ulcer

Probit plots of the mean uropepsin excretion values of all assays for each individual. The straight lines corresponding to these data have been fitted by inspection. The data for the healthy men have been taken from the previous paper (2). 
observed differences in variance could be due to chance grouping of the subjects.

It was also demonstrated by the method of probits that the mean excretion values for all of the subjects in either group (healthy or ulcer) could be arranged in the form of a normal distribution curve (Figure 2). The use of the data in this figure permits a prediction of the type of result that may be anticipated from a study of other ulcer patients or healthy subjects.

As is illustrated in Figure 2, a certain amount of overlapping was found to exist between the uropepsin excretion rates of individuals of the two groups. That the two groups are essentially dissimilar in spite of the observed degree of overlapping was demonstrated by the analysis of variance. Because of the overlapping the rate of uropepsin excretion cannot be utilized to determine whether or not all subjects definitely belong to either the normal or ulcer group.

The success of the prediction as to whether or not an individual belongs to one group or to the other can be visualized through a comparison of the probit plots in Figure 2. These data reveal that the mean value for uropepsin excretion in $\log$ units per hour was found to be 0.45 for the healthy subjects, whereas the mean value for the uropepsin excretion of patients with peptic ulcer was found to be $0.74 \mathrm{log}$ units per hour. It can also be seen that, of a group of normal subjects, $98 \%$ can be expected to show a mean excretion value of less than 0.88 units. Consequently, any subject with an excretion rate at this or higher levels can be predicted, with relative certainty, to belong outside of the healthy group. On the other hand, $27 \%$ of all ulcer patients can be expected to have a mean uropepsin excretion at this or higher levels. Accordingly, any one individual with an excretion rate at this or higher levels, has a much greater chance of belonging to the ulcer than to the normal group.

The probit plots show also that less than $8 \%$ of all normal patients will have mean excretion rates of $0.76 \mathrm{log}$ units per hour or more. On the other hand, $50 \%$ of all ulcer patients will have a uropepsin excretion rate at, or higher than, this level. Further, $50 \%$ of all normal individuals will have uropepsin excretion rates of $0.47 \mathrm{log}$ units per hour or less. On the other hand, less than $8 \%$ of ulcer patients can be expected to have mean ex- cretion rates in this low range. All of these examples indicate the value of the uropepsin excretion determination in predicting whether or not an individual belongs to the normal or ulcer group.

The results in Table $I$ of this report and Table III of the preceding report (2) indicate that a maximum of four consecutive night collections of urine will suffice for the determination of a stable mean uropepsin rate. Although a greater number of assays might yield a somewhat different mean value, the mean excretion value of the group as a whole will not be appreciably changed.

In spite of the limitations indicated by the foregoing discussion, the analysis of variance (Table II) reveals the limits of reliability within which the uropepsin assay can be utilized as an aid in the diagnosis of peptic ulcer. Its greatest usefulness might be found in the differentiation of patients with peptic ulcer from those with various gastric complaints but who do not have a true ulcer since those latter patients resemble healthy subjects in regard to their uropepsin excretion patterns. In view of the simplicity of the uropepsin assay and the lack of inconvenience to the patient, it may be useful in place of the somewhat more difficult and less convenient gastric analysis employed for such purposes. In this connection, it is of interest to note that, on several occasions, the results of the uropepsin assays performed on patients suspected of having ulcer indicated that they did not, in all probability, have such a lesion. This last impression was subsequently confirmed by gastroscopy or by operative findings.

Gottlieb (5) found a definite correlation between the height of uropepsin excretion and the production of acid by the stomach. Thus he noted the highest degree of uropepsin excretion in patients with marked hyperacidity. Since most ulcer patients characteristically display a rather marked hyperacidity, it could be anticipated, according to the observations of Gottlieb, that they would also display an increased uropepsin excretion. However, the correlation noted by Gottlieb between hyperacidity and increased uropepsin excretion may have been fortuitous. At any rate there is ample reason to believe that hyperacidity per se plays no role in regulating the excretion of uropepsin. As was indicated in the preceding reports $(1,2)$, uropepsin is probably derived from the endocrine secretion of the pepsinogen-produc- 
ing cells of the gastric mucosa. A great many studies would indicate a lack of functional interdependence between the pepsinogen-secreting cells and those secreting $\mathrm{HCl}$. Furthermore, our data indicate also that the amount of gastric secretion into the lumen of the stomach may bear no relationship at all to the amount of pepsinogen secreted directly into the blood.

We have had occasion to test the influence of the injection of histamine on uropepsin excretion by man and have been unable to conclude that histamine-induced acid production results in an increase in uropepsin excretion. Such results are in accord with those recently reported by Bucher and Anderson (6) who found that the injection of caffeine and histamine in oil exerted no influence on the uropepsin excretion of the cat although both are known to be powerful gastric stimulants. Furthermore, the results reported in the earlier papers in this series lead to the conclusion that factors such as food, alcohol, etc., which are known to influence the rate of secretion of the gastric juices, exert little influence in determining the rate of uropepsin excretion.

All of this would tend to indicate that pepsinogen is absorbed into the blood stream at a fairly constant rate that is characteristic of each individual, and that acid production by the stomach is not associated in a cause and effect relation with uropepsin excretion. It so happens that patients with peptic ulcer excrete uropepsin at a higher than normal rate and that many such patients also exhibit hyperacidity. Presumably the same factors that increase the endocrine activity of the pepsinogen-secreting glands in the ulcer patient also may operate to increase the rate of secretion of $\mathrm{HCl}$.

The relative degree of constancy of uropepsin excretion by ulcer patients is of some interest. Our earliest impression was to the effect that the uropepsin excretion of ulcer patients was characterized by wider fluctuation (7) than was the case for normal subjects. However, as noted above, the analysis of variance failed to confirm this impression. This would indicate that whatever factors are responsible for the increased rate of uropepsin excretion of ulcer patients operate at a fairly constant strength.

\section{SUMMARY AND CONCLUSIONS}

1. Men with peptic ulcer excrete uropepsin at a rate which is approximately twice the rate of healthy men.

2. Previous observations of the absence of uropepsin from the urine of patients with pernicious anemia have been confirmed.

3. Patients with gastric complaints but without peptic ulcer tend to resemble healthy men in regard to their excretion pattern.

4. The data suggest that uropepsin assays may be a useful adjunct in the diagnosis of peptic ulcer. The limits of its value are discussed.

5. The relationship between gastric hyperacidity and uropepsin excretion is discussed. It is concluded that there is no causal relationship between the two factors and that the frequent association of hyperacidity with increased uropepsin excretion is fortuitous and may be ascribed to the influence of unknown factors which may act to increase either acid production by the stomach and/or uropepsin excretion.

\section{ACKNOWLEDGMENT}

We wish to acknowledge the critical assistance of Dr. Henry W. Ryder of the Kettering Laboratory of Applied Physiology, who suggested the statistical methods used in the analysis of the data, and the aid rendered by Dr. I. H. Weiland in the collection of samples.

\section{BIBLIOGRAPHY}

1. Mirsky, I. A., Block, S., Osher, S., and Broh-Kahn, R. H., Uropepsin excretion by man. I. The source, properties and assay of uropepsin. J. Clin. Invest., 1948, 27, 818.

2. Broh-Kahn, R. H., Podore, C. J., and Mirsky, I. A., Uropepsin excretion by man. II. Uropepsin excretion by healthy men. J. Clin. Invest., 1948, 27, 825.

3. Snedecor, G. W., Statistical Methods. Iowa State College Press, Ames, Iowa, 1946, Ed. 4.

4. Farnsworth, E. B., Speer, H., and Alt, H. L., The quantitative determination of a pepsin-like substance in the urine of normal individuals and of patients with pernicious anemia. J. Lab. \& Clin. Med., 1946, 31, 1025.

5. Gottlieb, E., Untersuchungen über die Pro-pepsinmengen im Blut und Harn. Skand. Arch. für Physiol., 1924, 46, 1.

6. Bucher, G. H., and Anderson, A., The uropepsin output in cats given histamine-caffeine in beeswax. Federation Proc., 1948, 7, 16.

7. Podore, C. J., Broh-Kahn, R. H., and Mirsky, I. A., Uropepsin excretion in man. Federation Proc., 1948, 7, 95. 